\title{
Incidence of Solid Organ Injury after Isolated Blunt Abdominal Trauma in Pediatric Patients in Tanta University Hospital
}

Nahla El-Sebaie Mostafa ${ }^{1}$, Khalid Ahmed Ismail ${ }^{2}$, Akram Mohammed Elbatarny ${ }^{2}$ and Khalid Mohammed ElShimy ${ }^{2}$.

${ }^{1}$ Emergency Medicine \&Traumatology Department, Faculty of Medicine, Tanta University, Tanta 35127, Egypt.

${ }^{2}$ General surgery Department, Faculty of Medicine, Tanta University, Tanta 35127, Egypt.

Corresponding author: Nahla El-Sebaie Mostafa, Email: edr.nahla@gmail.com ,Tel: +2 01068720398

\begin{abstract}
Background: Trauma is considered the leading cause of children death worldwide. The most common cause of death in pediatric trauma is abdominal trauma.
\end{abstract}

Aim of the study: This study aimed to evaluate incidence of solid organ injury after blunt abdominal trauma (BAT) in pediatric patients.

Patients and Methods: The study was conducted on pediatric patients admitted to Emergency Department, Tanta University Hospital with suspected solid organ injury after isolated blunt abdominal trauma.

Results: In this study, we had 119 patients with blunt abdominal trauma presented to emergency department. FAST (Focused Assessment with Sonography for Trauma) showed that intra-peritoneal free fluid (IPFF) only with no solid organ injury was found in 39.5\%. Splenic injury was found in about $38.7 \%$ of patients while hepatic injury was present in about $18.5 \%$. Renal injury was found in about $1.7 \%$. Both renal and splenic injury were present in about $0.8 \%$.

Conclusion: Splenic injury was the most common solid organ to be injured in blunt abdominal trauma in pediatrics. Keywords: Pediatric, blunt trauma, abdominal, intra-abdominal injury.

\section{INTRODUCTION}

Trauma in children is still a considerable cause of disability and death in spite of injury prevention successes and attention to child safety improvement ${ }^{[1,}$ 2].

Intra-abdominal injury (IAI) remains the significant cause of morbidity in children. Early recognition of IAI is important to decrease both morbidity and mortality ${ }^{[3,4]}$.

Mechanisms of trauma hinge upon the age of the children. In young infants, non-accidental injury is most common while in toddlers, falls are the predominant ${ }^{[5]}$. Whereas for older children, road traffic accidents predominate ${ }^{[5,6]}$.

The Advanced Trauma Life Support (ATLS) protocol of the American College of Surgeons' Committee remains the standard algorithm for the evaluation and management of traumatized patients ${ }^{[7]}$.

Liver and spleen are considered the most common solid organs to be injured in blunt abdominal trauma in children, then kidneys. Hollow viscus injuries are the next most common form of injury, followed by injuries to the abdominal vasculature ${ }^{[8]}$.

The study aimed to evaluate incidence of solid organ injury after blunt abdominal trauma in pediatric patients in Emergency Department.

\section{Ethics of the Study:}

An approval from the Ethical Committee was obtained. An informed written consent was taken from each patient after explanation of benefits and risks. Privacy of all patient's data was secured. There was a code number for every patient file that included all investigations.

\section{PATIENTS AND METHODS}

This study was carried out on 119 patients who were presented to Tanta University Emergency Hospital from October 2017 till October 2018. Patients younger than 18 years with isolated blunt abdominal trauma within 24 hours were included while patients older than 18 years old, patients with history of trauma more than 24 hours and patients with associated chronic diseases were excluded.

All patients were subjected to full history taking from the patient or his/her relatives or a witness. According to ATLS, management consisted of rapid primary survey, resuscitation of vital functions, more detailed secondary survey and finally the initiation of definitive care.

Routine laboratory investigations including $\mathrm{CBC}$, $\mathrm{ABO} \mathrm{Rh}$ cross-matching, coagulation profile (PT, PTT, and INR) and renal and liver function test have been done to all patients. Radiological investigations including FAST, Plain chest $\mathrm{x}$-ray, Plain pelvis $\mathrm{x}$-ray and Plain erect abdominal $\mathrm{x}$-ray have been done to our patients.

Abnormal FAST findings were defined as: free fluids or injuries to solid organs. The views of Morrison's pouch, the peri-splenic region, pelvis, and pericardium are evaluated for the presence of free intra-peritoneal fluid. 


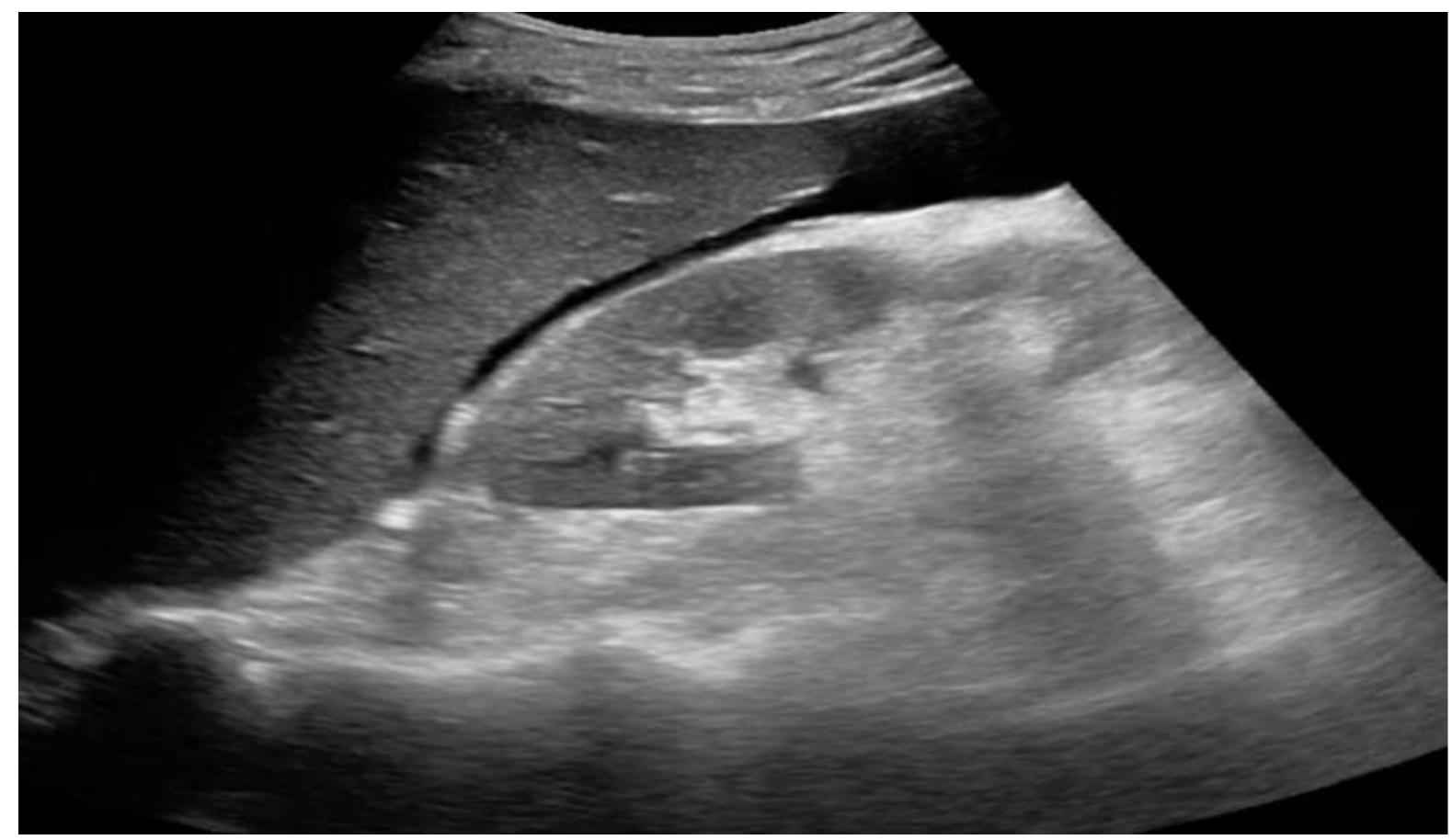

Figure (1): FAST of 14 years old female falling from height showing IPFF in Morrison's Pouch.

\section{Statistical analysis}

Data were analyzed using Statistical Program for Social Science (SPSS) version 15.0. Quantitative data were expressed as mean \pm standard deviation (SD). Qualitative data were expressed as frequency and percentage. The following tests were done: Chisquare test was used when comparing between nonparametric data. A one-way analysis of variance (ANOVA): when comparing between more than two means.

\section{RESULTS}

Our study was conducted on 119 patients who were presented to Emergency Department, Tanta University Hospital (TUH) from October 2017 to October 2018 for evaluation of the incidence of solid organ injury after blunt abdominal trauma in pediatric patients.

Our patient's age ranged between 3 months -18 years. We had 68 males and 51 females (Table 1). The most frequent mode of trauma was road traffic accidents in all studied groups $(57.1 \%)$, followed by falling from height $(38.6 \%)$ and direct abdominal trauma patients $(4.1 \%)$ as shown in table (2).

FAST examination showed that IPFF only with no organ injury was found in 47 cases $(39.5 \%)$ while solid organ injury was proven in 72 cases $(60.5 \%)$ as follows; splenic injury and hepatic injury were found in 46 cases $(38.7 \%)$ and 22 cases $(18.5 \%)$ respectively. Renal injury was found in 2 cases $(1.68 \%)$ while only one case had both renal and splenic injury $(0.84 \%)$ as shown in table (3). Computed tomography (CT) was done in 70 cases only. The remaining cases were not subjected to CT due to hemodynamic instability. All patients were admitted in Tanta University Hospital Emergency Department either in a ward or ICU. In this study, 48 cases were admitted in ICU and the remaining were admitted in pediatric surgery ward. There was no mortality in our cases.

Table (1): Patients as regard sex

\begin{tabular}{|l|l|l|}
\multirow{2}{*}{ Variables } & \multicolumn{2}{|l|}{ Sex (years) $(\mathbf{N}=\mathbf{1 4})$} \\
\cline { 2 - 3 } & $\mathrm{N}$ & $\%$ \\
\hline Male & $\mathbf{6 8}$ & $\mathbf{5 7 . 1 4}$ \\
\hline Female & 51 & 42.86 \\
\hline Total & 119 & 100 \\
\hline
\end{tabular}

Table (2): Patients as regard mode of trauma

\begin{tabular}{|l|l|l|}
\hline \multirow{2}{*}{ Variables } & \multicolumn{2}{|c|}{ Mode of trauma } \\
\cline { 2 - 3 } Road traffic accident & $\mathbf{N}$ & $\%$ \\
\hline Falling from height & 68 & 57.14 \\
\hline Direct abdominal trauma & 46 & 38.66 \\
\hline Total & 5 & 4.20 \\
\hline
\end{tabular}

Table (3): Patients as regard FAST finding

\begin{tabular}{|l|l|l|}
\hline \multirow{2}{*}{ Variables } & FAST & \\
\cline { 2 - 3 } & N & $\%$ \\
\hline IPFF & 47 & 39.5 \\
\hline Splenic contusion + IPFF & 46 & 38.7 \\
\hline Hepatic lesion + IPFF & 22 & 18.5 \\
\hline Pancreatic lesion + IPFF & 1 & 0.8 \\
\hline $\begin{array}{l}\text { Renal + IPFF } \\
\text { Splenic contusion + Renal } \\
\text { + IPFF }\end{array}$ & 2 & 1.7 \\
\hline Total & 1 & 0.8 \\
\hline
\end{tabular}




\section{DISCUSSION}

Although there is a great success in therapeutic measures in trauma intensive care units, BAT still remains the cause of deaths in children and is considered the second cause of emergency department patients after infections ${ }^{[9]}$. The age of our patients ranged from 3months-18 years old with a mean of age 7.4 years. Our results are concordant with, Khirallaha et al. ${ }^{[11]}$ and Djordjevic et al. ${ }^{[10]}$. In these studies, the range was from 2-18 years, and 15 months -15 years respectively.

In our study, we found that 68 cases were males. This can be explained by the fact that boys in our community are more active and accordingly more exposed to trauma. In agreement with our results, Khirallaha et al. ${ }^{[11]}$ studied 250 children where 145 were boys and 105 were girls. In Ndour et al. ${ }^{[4]}$ study on BAT conducted on 55 cases, boys were $78.1 \%$ and girls were $21.8 \%$.

We found the most frequent occurrence was RTAs in 68 cases. Ndour O, et al. study (2017) ${ }^{[4]}$ also reported that the most frequent occurrence was road traffic accidents with 28 cases, a rate of $50.9 \%$.

FAST is the investigation of choice for identification of hemo-peritoneum in abdominal trauma ${ }^{[12]}$.

In our study all patients were subjected to FAST. In children, spleen is bigger and protrudes from ribs cage. Therefore, it is usually injured in blunt abdominal trauma in children ${ }^{[13]}$.

Djordjevic et al. ${ }^{[3]}$ reported that splenic injury presented in $38.7 \%$ of patients, $32.25 \%$ of patients were renal injury, pancreatic injury was $16.12 \%$ and $12.9 \%$ were hepatic injury.

\section{CONCLUSIONS AND RECOMMENDATIONS:}

1. In our community the age most affected with BAT ranges between 7-11 years old and males are more affected than females.

2. FAST is an important diagnostic tool for assessment of unstable trauma children and determining who requires urgent lifesaving laparotomy.

3. Spleen is often involved in blunt abdominal trauma in pediatrics.

4. FAST for trauma is not a replacement for CT. But, in hemodynamically unstable patients, FAST is feasible, and positive FAST findings can determine patients for urgent laparotomy.

\section{REFERENCES}

1. Falcone Jr RA, Brown RL, Garcia VF (2007): The Epidemiology of Infant Injuries and Alarming Health Disparities. Journal of Pediatric Surgery, 42 (1): 172- 7.

2. Mendelson KG, Fallat ME (2007): Pediatric Injuries: Prevention to Resolution. Surgical Clinics, 87 (1): 207-2.

3. Djordjevic I, Slavkovic A, Marjanovic Z et al. (2015): Blunt Trauma in Paediatric Patients-Experience from a Small Centre. The West Indian Medical Journal, 64 (2): 126-30.

4. Ndour O, Camara S, Tendart V et al. (2017): Blunt Abdominal Trauma in Child: Epidemiological, Diagnostic, and Therapeutic Analysis of 55 Cases. African Journal of Trauma, 6 (1): 1

5. Cullen PM (2012): Paediatric Trauma. Continuing Education in Anaesthesia, Critical Care \& Pain, 12 (3): 157-61.

6. Baren JM, Rothrock SG, Brennan J et al. (2007): Pediatric Emergency Medicine. Elsevier Health Sciences. Chapter 15, Pp: 149-53???

7. Carmont MR (2005): The Advanced Trauma Life Support Course: A History of its Development and Review of Related Literature. Postgraduate Medical Journal, 81 (952): 87-91.

8. Schacherer N, Miller J, Petronis K (2014): Pediatric Blunt Abdominal Trauma in the Emergency Department: Evidence-Based Management Techniques. Pediatric Emergency Medicine Practice, 11 (10): 1-23.

9. Aslar AK, Kuzu MA, Elhan AH et al. (2004): Admission Lactate Level and the APACHE II Score are the Most Useful Predictors of Prognosis Following Torso Trauma. Injury, 35 (8): 746-52.

10. Djordjevic I, Slavkovic A, Marjanovic Z et al. (2015): Blunt Trauma in Paediatric Patients-Experience from a Small Centre. The West Indian Medical Journal, 64 (2): 126-30.

11. Kumar BN, Akulwar AV (2015): Renal Artery Injury in Paediatric Blunt Abdominal Trauma. Medical Journal, Armed Forces India, 71 (1): S261.

12. Patel NY, Riherd JM (2011): Focused Assessment with Sonography for Trauma: Methods, Accuracy, and Indications. The Surgical Clinics of North America, 91 (1): 195-207.

13. Miele V, Trinci M (2014): Imaging Trauma and Polytrauma in Pediatric Patients. Springer. Chapter 4 ,Pp: $65-100$ 